\title{
Prospects of estrogen receptor $\beta$ activation in the treatment of castration-resistant prostate cancer
}

\author{
Julia Gehrig ${ }^{1}$, Silke Kaulfuß ${ }^{1}$, Hubertus Jarry², Felix Bremmer ${ }^{3}$, Mark Stettner ${ }^{4}$, \\ Peter Burfeind ${ }^{1}$ and Paul Thelen ${ }^{5}$ \\ ${ }^{1}$ Institute of Human Genetics, University Medical Center Goettingen, Germany \\ ${ }^{2}$ Department of Experimental Endocrinology, University Medical Center Goettingen, Germany \\ ${ }^{3}$ Institute of Pathology, University Medical Center Goettingen, Germany \\ ${ }^{4}$ Department of Neurology, University of Essen, Germany \\ ${ }^{5}$ Department of Urology, University Medical Center Goettingen, Germany \\ Correspondence to: Paul Thelen, email: pthelen@gwdg.de \\ Keywords: ADT, estrogen receptor $\beta, 8 \beta$-VE2, androgen receptor, therapy resistance \\ Received: July 20, $2016 \quad$ Accepted: March 08, $2017 \quad$ Published: March 23, 2017 \\ Copyright: Gehrig et al. This is an open-access article distributed under the terms of the Creative Commons Attribution License \\ (CC-BY), which permits unrestricted use, distribution, and reproduction in any medium, provided the original author and source \\ are credited.
}

\section{ABSTRACT}

Advanced prostate cancer can develop into castration-resistant prostate cancer (CRPC). This process is mediated either by intratumoral ligand synthesis or by mutations or aberrations of the androgen receptor (AR) or its cofactors. To date, no curative therapy for CRPC is available, as AR-targeted therapies eventually result in the development of resistance. The human prostate cancer cell line VCaP (vertebral cancer of the prostate) overexpresses AR and its splice variants (ARVs) as a mechanism of resistance to androgen-deprivation therapy (ADT) of external and intratumoral origin. In the present study, we demonstrate that stimulating estrogen receptor $\beta$ activity with the specific agonist 8 $\beta$-VE2 in VCaP cells in successive stages of ADT induced a time- and dose-dependent decrease in cell survival and an increase in apoptosis. Furthermore, 8 $\beta$ VE2 treatment reduced the overexpression of the AR as well as ARVs in VCaP cells under maximum ADT. Our results indicate that decreased survival of the androgen-dependent CRPC cells employing apoptosis together with the regulative effect on AR expression could have beneficial effects over current AR-targeting therapies.

\section{INTRODUCTION}

Prostate cancer is one of the most frequently diagnosed cancers and a leading cause of cancer-related deaths in Western society. For patients who develop progressive castration-resistant prostate cancer (CRPC), therapeutics targeting androgen receptor (AR) signaling have been proven to significantly prolong survival [1]. Regardless of previous treatments, novel therapies can still target AR activity that remains after preceding therapies. These new therapies include potent inhibitory AR-binding ligands, such as enzalutamide, or agents that exhaustively block androgen biosynthesis from all relevant sources, such as the selective inhibitor of CYP17A1, abiraterone. Still, the mechanisms implicated in the development of resistance to AR inhibition in prostate cancer are multiple and complex, involving virtually all classes of genomic alteration and leading to a host of selective/adaptive responses [2]. Therefore, even the most promising and highly effective new agents might eventually fail because of newly developed therapy resistance and subsequent failure. Moreover, efficient androgen deprivation and complete receptor blockade have not proven to be as complementary as anticipated or desired. This phenomenon of cross resistance became evident in studies of sequential or combinatorial use of these new individually effective drugs [3]. Two major aberrations were identified as the most likely underlying causes for the acquisition of therapy resistance and cross-resistance. The first is the occurrence of AR mutations, which lead to promiscuous employment of antiandrogens or other steroids for AR activation [4-7]. The second, which is observed more frequently, is the expression of different constitutively 
active AR splice variants [8]. Both mechanisms of resistance are observed after treatment with abiraterone as well as enzalutamide and result in the resumption of AR activity. Nevertheless, combinational therapeutic approaches targeting AR signaling and alternative oncogenic pathways are considered reasonable for patients with CRPC [9]. Taking into account that all approaches targeting the AR axis ultimately result in therapeutic failure, the search for alternative pathways becomes crucial.

Estrogen receptor $\beta$ (ER $\beta$, also known as ESR2) has been shown to have a role as a tumor suppressor in prostate cancer in various reports. The loss of ER $\beta$ expression correlates with increased proliferation in the ER $\beta$-knock out/ TRAMP (transgenic adenocarcinoma of mouse prostate) mouse model [10] as well as in human prostate cancer tumor tissue $[11,12]$. Although ER $\beta$ is downregulated during prostate cancer progression [13], the activation or upregulation of ER $\beta$ inhibits tumor progression and induces cell cycle arrest and apoptosis in prostate cancer [14-16]. Our previous work focused on the activation of ER $\beta$ by subtype-specific ligands or by reversing the epigenetic silencing of histone modifications with the consequent anti-androgenic function of ER $\beta$ [17-19]. Therefore, AR downregulation by ER $\beta$ activation with subtype-selective ligands might achieve all-encompassing AR inhibition, including promiscuous gain-of-function AR mutations and splice variants acquired in earlier treatments. In addition, this concept should not by itself select for AR gain-offunction mutations or antiandrogen-to-androgen conversion because ER $\beta$-targeted antiandrogen strategies do not involve inhibitory AR ligands with high affinity to AR. In this study, we evaluated the ER $\beta$-selective ligand $8 \beta$-VE2 because of its antiandrogen features [20]. We used the prostate cancer bone metastasis cell model $\mathrm{VCaP}$, which exists in three different stages of androgen-deprivation therapy (ADT) (androgen-sensitive, castration-resistant and under inhibition of intratumoral steroidogenesis by abiraterone acetate) to elucidate therapy sequencing options under obviation of cross resistance.

\section{RESULTS}

\section{Generating different populations of VCaP cells}

We aimed to investigate the influence of an ER $\beta$ specific ligand on a cell system that mimics the three different stages of ADT in humans. Therefore, the ARoverexpressing $\mathrm{VCaP}$ cells were either treated with testosterone to reset the cells to an androgen-dependent state before first-line ADT, comparable to early pretreatment conditions, or with abiraterone to drive $\mathrm{VCaP}$ cells into maximal ADT, i.e., all androgen sources, including intratumoral androgen synthesis, suppressed, as in second-line ADT (Figure 1A). Both qRT-PCR (Figure $1 \mathrm{~B})$ and western blot analyses (Figure 1C) were performed for the three $\mathrm{VCaP}$ cell variants, androgen-sensitive $\mathrm{VCaP}$ cells (VCaP rev), VCaP cells under ADT (CRPC) and
VCaP cells treated with abiraterone (VCaP AA), to confirm differential gene expression for prostate cancer-relevant genes under increasing ADT. AR mRNA expression was significantly upregulated from low levels in $\mathrm{VCaP}$ rev cells to VCaP cells, and AR mRNA expression was further upregulated under increasing ADT in VCaP AA cells, albeit not significantly. Similarly, AR protein expression in $\mathrm{VCaP}$ rev cells was downregulated by $56 \%$, and PSA expression was reduced by $54 \%$ compared with VCaP control cells. Of note, this pretreatment condition presents with normal AR expression and no obvious PSA in the presence of low testosterone, whereas initial androgen withdrawal revealed increased castration-resistant features of AR and elevated PSA without external testosterone. Further upregulated expression of the AR (5.8-fold) and PSA expression (almost 2-fold) was observed in VCaP AA cells compared with those in untreated $\mathrm{VCaP}$ cells. Furthermore, splice variants of the AR (ARVs) could be detected only in VCaP AA cells concomitant with the maximum upregulation of full-length AR. qRT-PCR expression analyses revealed ARV7 as one representative ARV for the molecular structure visualized by the $\mathrm{N}$-terminal AR antibody (data not shown). The western blot analysis indicates that ER $\beta$ expression was not aligned with increasing castration resistance mechanisms as demonstrated for AR, ARVs and PSA but had maximal expression in the castration-resistant pre-abiraterone stage.

Control experiments in establishing this CRPC cell model revealed VCaP cells are definitely androgensensitive, thus DHT (10 nM) could induce AR promoter activity. Most important for this project was, however, that there is no such activity from the compound $8 \beta-\mathrm{VE} 2$ (Supplementary Figure 1).

\section{Testing of the efficacy of the ER $\beta$-specific agonist 8及-VE2}

The different stages of ADT represented by $\mathrm{VCaP}$ rev, $\mathrm{VCaP}$, and VCaP AA were used to investigate the effect of ER $\beta$ activation on increasing ADT stages. Therefore, the cells were treated with the ER $\beta$-specific agonist $8 \beta$-VE2, and cell survival, apoptosis induction and gene expression were examined. First, different dosages of $8 \beta$-VE2 were tested in $\mathrm{VCaP}$ cells to determine drug efficacy (Supplementary Figure 2). Concentrations of $5 \mu \mathrm{M}$ and $25 \mu \mathrm{M} 8 \beta$-VE2 showed significant reduction of cell survival and induction of apoptosis and were used for further experiments. A concentration of $50 \mu \mathrm{M} 8 \beta-\mathrm{VE} 2$ led to a diminished expression of housekeeping genes (data not shown), and were therefore excluded from further experiments.

\section{ERß activation led to AR and ARV downregulation in ADT in VCaP and VCaP AA cells}

Because AR signaling based on AR overexpression and the occurrence of AR splice variants was retrievable 
in our cell model of therapy through the sequence of intensifying ADT and is indicated by PSA progression as in clinical surveillance, we evaluated the effect of ER $\beta$ activation on AR expression. In the least malignant and androgen-sensitive stage, as indicated by low AR expression, $8 \beta$-VE2 treatment of $\mathrm{VCaP}$ rev cells did not further improve their low malignancy. On the contrary, especially under high concentrations of $8 \beta$-VE2, AR expression was significantly upregulated at both the mRNA and protein level (Figure 2A, 2B). Therefore, $\mathrm{ER} \beta$ targeting as a first-line antiandrogen measure is not an option. However, in castration resistance and, most tellingly, at the brink of therapy resistance, AR mRNA was downregulated in VCaP cells by $40 \%$ and in $\mathrm{VCaP}$ AA cells by $70 \%$ (Figure 2A). Concordantly, AR protein expression decreased by $52 \%$ in VCaP cells and by $90 \%$ in $\mathrm{VCaP} A \mathrm{~A}$ cells after $8 \beta-\mathrm{VE} 2$ treatment (Figure $2 \mathrm{~B}$ ). In $8 \beta$-VE2-treated VCaP AA cells, the expression of ARVs was also remarkably downregulated by $72 \%$. Activation of $\mathrm{ER} \beta$ in VCaP AA cells with $5 \mu \mathrm{M} 8 \beta$-VE2 already induced the desired downregulation of AR and ARVs, and further downregulation of the expression of AR and ARVs was obtained using $25 \mu \mathrm{M} 8 \beta$-VE2 (Figure 2B).

\section{ER $\beta$ activation reduced cell survival and induced apoptosis in different VCaP cell populations}

To investigate the therapeutic potential of ER $\beta$ activation at the cellular level, both tumor cell survival and induction of apoptosis were assayed in the following experiments. The three $\mathrm{VCaP}$ populations ( $\mathrm{VCaP}$ rev, $\mathrm{VCaP}$, and VCaP AA) were treated with 5 and $25 \mu \mathrm{M} 8 \beta$ VE2 or with DMSO as the control. Both the cell survival rate (Figure 3A, 3C, and 3E) and induction of apoptosis (Figure 3B, 3D, and 3F) were measured simultaneously using the ApoTox-Glo ${ }^{\mathrm{TM}}$ Triplex Assay. All three treated VCaP cell populations showed a significantly reduced cell survival rate of up to $60 \%$ relative to that of control cells. In addition, apoptosis was observed in all VCaP populations and was between three- and five-fold higher than that of control cells. These cell survival and apoptosis effects occurred in a time- and concentration-dependent

A.

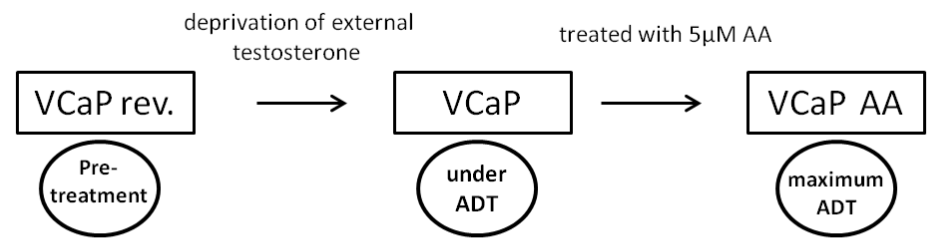

B.

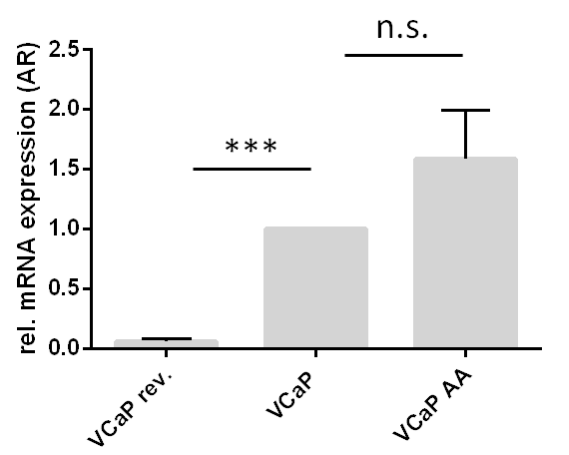

C.
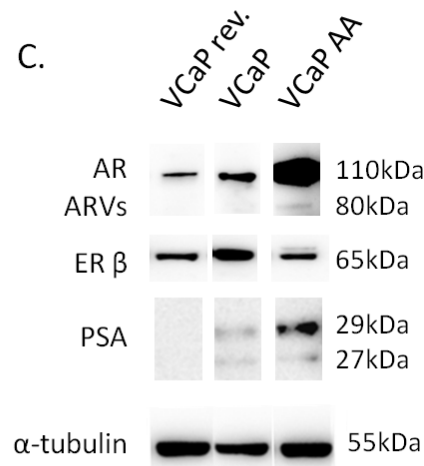

Figure 1: The VCaP variants differ in their expression of prostate cancer-relevant genes. (A) VCaP rev were cultured with $1 \mathrm{nM}$ testosterone over seven months, whereas VCaP AA were treated continuously with $5 \mu \mathrm{M}$ abiraterone acetate. The three cells lines represent three different levels of androgen deprivation: VCaP rev, no therapy, subphysiological testosterone $(0.3 \mathrm{ng} / \mathrm{ml})$; VCaP, CRPC under first-line therapy (no detectable testosterone, data not shown); VCaP AA, CRPC under maximal, including intratumoral, ADT. (B) mRNA expression of the AR was measured by quantitative RT-PCR in all VCaP cell variations. AR expression in VCaP rev cells was significantly lower compared with that in $\mathrm{VCaP}$ control cells. AR mRNA expression in $\mathrm{VCaP}$ AA cells was not significantly higher than in $\mathrm{VCaP}$ control cells. The experiment was performed in triplicate. ${ }^{*} \mathrm{P}<0.05, * * \mathrm{P}<0.01, * * * \mathrm{P}<0.0001$, n.s. (not significant) compared with $\mathrm{VCaP}$ cells. (C) Representative western blot showing the three $\mathrm{VCaP}$ populations, $\mathrm{VCaP}$ rev, VCaP, and VCaP AA. Total protein was extracted, and immunoblots were probed with AR-specific, ER $\beta$-specific, and PSA-specific antibodies. In VCaP rev cells, AR and PSA expression levels were remarkably lower than in VCaP cells. In VCaP AA cells, the AR and PSA expression levels were increased compared with those in $\mathrm{VCaP}$ cells. In $\mathrm{VCaP}$ rev as well as in VCaP AA cells, the ER $\beta$ expression was lower than in VCaP cells. The data represent two independent experiments, which were performed in duplicate. $\alpha$-tubulin was used as a loading control. 
manner and were observed in all three ADT modes. Most strikingly, tumor cell survival was lower, and apoptosis intensified faster and to the highest extent in VCaP AA cells, which are pending therapy failure; therefore, in this situation, switching therapies should be considered.

\section{DISCUSSION}

Persistent androgen receptor signaling under sequenced therapies for metastatic castration-resistant prostate cancer (mCRPC) is the main obstacle for durable treatment benefit because therapy resistance occurs for most initially effective treatments. This statement is true even after the advent of the most effective ADTs, such as abiraterone acetate, or multifunctional new generation AR inhibitors, such as enzalutamide. Although these drugs have different molecular targets (abiraterone inhibits steroidogenesis, and enzalutamide competitively binds AR with high affinity), resistance to these therapies most likely shares a common denominator [8]. This common molecular medium of androgen-directed therapy failure most likely accounts for the phenomenon of cross resistance, i.e., effective treatments may lose much of their individual potential when applied in the second position. This molecular structure causing therapy failure for both abiraterone and enzalutamide has recently been identified potentially as constitutive active AR splice variants, represented by AR-V7 [8]. A liquid biopsy analysis including this predictive AR modification from circulating prostate cancer cells has since been established. This ability to determine key resistance-mediating AR modifications facilitates a personalized approach for

A.

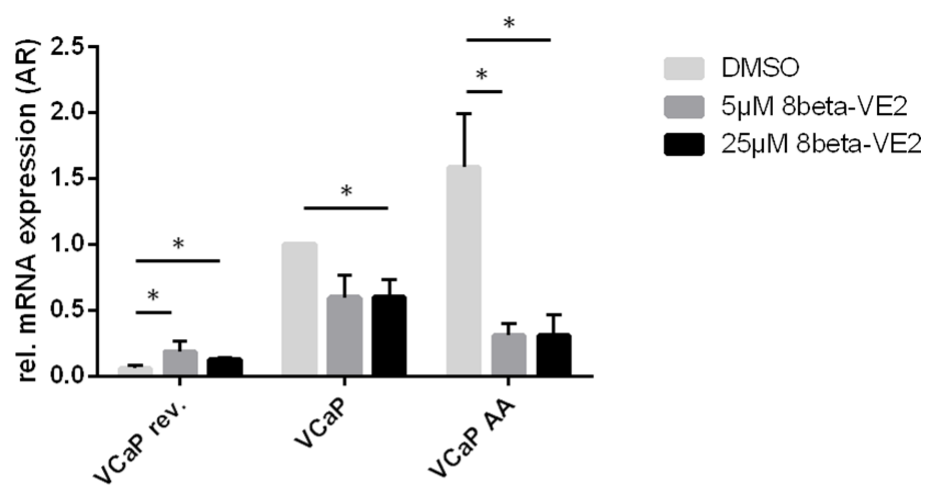

B.

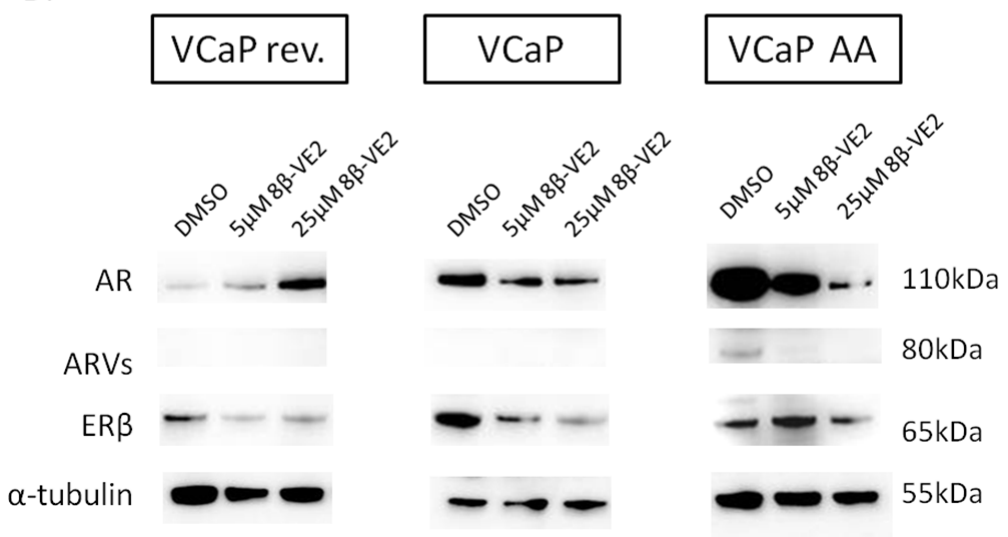

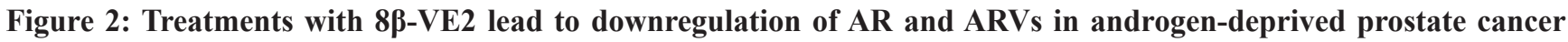
cells. (A) mRNA expression of the AR was measured by quantitative RT-PCR. VCaP rev, VCaP, and VCaP AA cells were treated with DMSO, $5 \mu \mathrm{M} 8 \beta$-VE2 and $25 \mu \mathrm{M} 8 \beta$-VE2. AR expression was strongly reduced after treatment with $8 \beta$-VE2 in VCaP control and VCaP AA cells. In $\mathrm{VCaP}$ rev cells, upregulation of AR mRNA expression could be observed. The data represent the mean \pm s.d. of three independent experiments, which were performed in duplicate. $* \mathrm{P}<0.05, * * \mathrm{P}<0.01, * * * \mathrm{P}<0.0001$ compared with DMSO control. (B) A representative western blot is shown of $\mathrm{VCaP}$ rev, $\mathrm{VCaP}$, and $\mathrm{VCaP}$ AA cells treated with DMSO, $5 \mu \mathrm{M} 8 \beta$-VE2, or $25 \mu \mathrm{M} 8 \beta$-VE2. Total protein was extracted, and immunoblots were probed with AR-specific or ER $\beta$-specific antibodies. A reduction in protein expression of the AR was detected in $\mathrm{VCaP}$ and in $\mathrm{VCaP} A A$ cells after $8 \beta$-VE2 treatment. In 8 $\beta$-VE2-treated VCaP AA cells, the expression of ARVs was remarkably downregulated. In contrast, $\mathrm{VCaP}$ rev cells with low initial expression showed upregulated AR expression. In all three cell populations, downregulation of ER $\beta$ protein was observed at high $8 \beta$-VE2 concentration. The data represent two independent experiments, which were performed in duplicate. $\alpha$-Tubulin was used as a loading control. 
decision-making in therapeutic sequences and may considerably improve prolonged prostate cancer treatment and patient survival [23].

We were able to recapitulate resistance patterns in cells from that observed after first-line ADT to complete ADT in our representative in vitro models of $\mathrm{VCaP}$ bone metastatic cells. The therapeutic sequence commenced from $\mathrm{VCaP}$ rev cells, which depend on the low testosterone concentration of $1 \mathrm{nM}(0.3 \mathrm{ng} / \mathrm{ml})$ and exhibit a normal level of AR expression (Figure $1 \mathrm{~A}-1 \mathrm{C})$. This cell model should represent hypogonadal therapy-naïve patients and displays androgen sensitivity. Therefore, these cells are susceptible to first-line ADT, i.e., deprivation of external androgens [19]. As observed in our cell model, first-line androgen deprivation eventually caused castration resistance (VCaP) with AR signaling depending on intratumoral steroidogenesis and AR sensitized by overexpression [2]. This cell model was treated with the clinically approved CRPC drug abiraterone to eliminate intratumoral steroidogenesis to further fortify AR overexpression (Figure $1 \mathrm{~B}$ and 1C) and added AR splice variants (80 kDa, Figure 1C).
This latter condition is considered therapy-resistant and a therapy switch from ADT to AR blockade, e.g., abiraterone to enzalutamide, is not recommended due to pending cross resistance $[22,24]$. Under these AR conditions, abiraterone is no longer effective because AR splice variants are constitutively active and unreceptive to ADT, and enzalutamide cannot bind to this structure due to the lack of an AR ligand binding domain in this structure. Our model clearly shows the potential of AR splice variants to exhibit constitutive activity because the classical androgen-regulated gene PSA is expressed under complete androgen deprivation and in the absence of external androgens, i.e., virtually androgen-free PSA expression (Figure 1C).

The detection of AR splice variants by liquid biopsies for personalized therapy sequencing excluded switching to other AR-targeted therapies; thus, chemotherapy remains an option [25]. To overcome the predicament of cross resistance if CRPC therapy of next-generation ADT fails, and AR blockade by flutamide, bicalutamide or enzalutamide is less effective, we applied ER $\beta$ activation as an antiandrogen treatment
A.

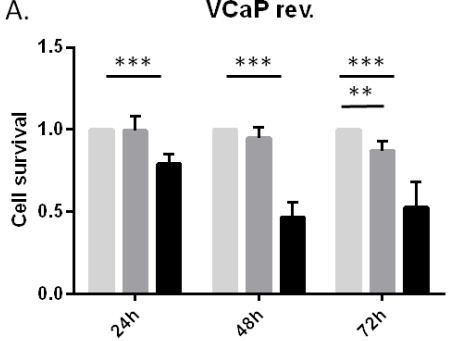

C.

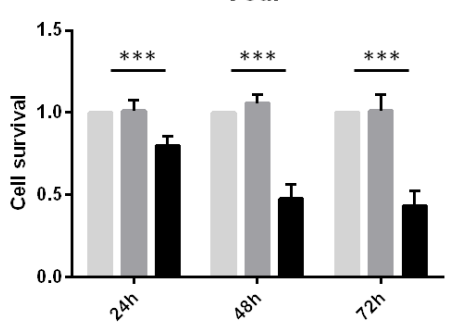

E.

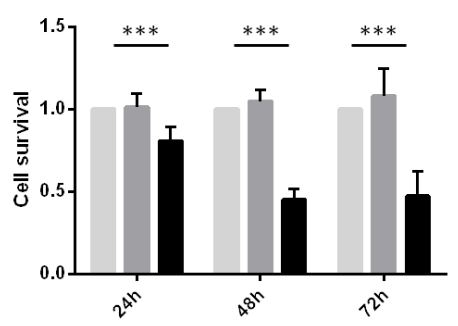

B. VCaP rev.
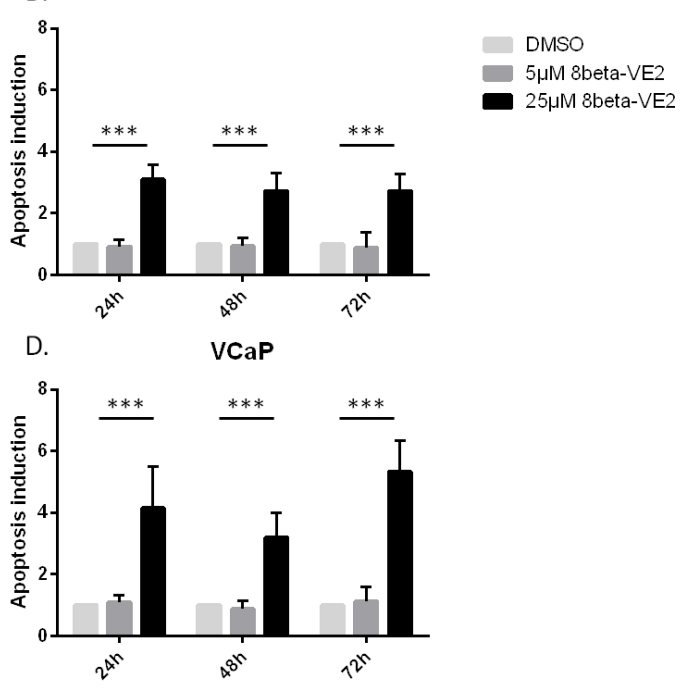

F.

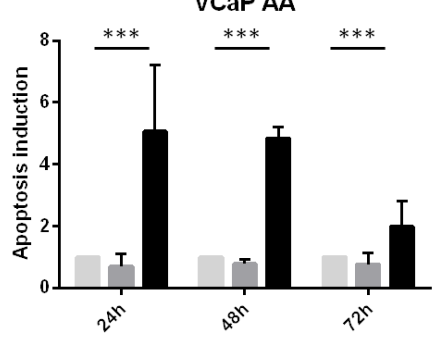

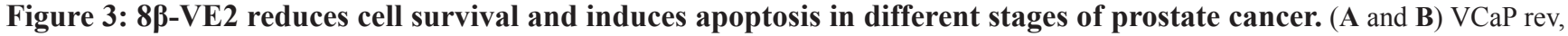
$(\mathbf{C}$ and $\mathbf{D}) \mathrm{VCaP}$, and (E and $\mathbf{F}) \mathrm{VCaP} A A$ cells were treated with DMSO, $5 \mu \mathrm{M} 8 \beta$-VE2, or $25 \mu \mathrm{M} 8 \beta$-VE2 and (A, C, E) cell survival and (B, D, F) apoptosis were measured 24, 48, and $72 \mathrm{~h}$ after the start of treatment. All three VCaP cell populations showed a downregulated cell survival rate compared with that of control cells. In addition, induction of apoptosis could be observed in all VCaP populations. The data represent the mean \pm s.d. of three independent experiments, which were performed in duplicate. ${ }^{*} \mathrm{P}<0.05, * * \mathrm{P}<0.01, * * * \mathrm{P}<0.0001$ compared with DMSO control. 
using the ER $\beta$-selective agonist $8 \beta$-VE2 [26, 17]. Although $8 \beta$-VE2 showed potential as a general prostate cancer drug by decreasing cell survival and increasing tumor cell apoptosis in all cell variants (Figure 3), there is no just cause to replace approved first-line and next-generation ADT in androgen-sensitive prostate cancer or CRPC considering the effects we obtained on the pivotal target AR (Figure 2B). However, putative therapeutic resistance from $A R$ overexpression and splice variants can be potentially rectified with this ER $\beta$ selective agonist (Figure 2B, VCaP AA). The reciprocal mechanism of AR/AR-Vs downregulation under ER $\beta$ activation appears to perform best with a moderate $8 \beta$ $\mathrm{VE} 2$ concentration of $5 \mu \mathrm{mol} / \mathrm{L}$. Increased concentrations further limit AR expression but no longer on the basis of the cogent counteraction. Interesting in a mechanistic sense, the counteraction of AR and ER $\beta$ expression was demonstrated in CRPC rev cells (Figure 2B) where ER $\beta$ downregulation caused the upregulation of $A R$ expression. This finding confirms our previous data from ER $\beta$ functional analyses with RNA interference in LNCaP cells, when ER $\beta$ knock-down caused rising PSA indistinguishable from an androgen stimulus [17]. Also in CRPC represented by $\mathrm{VCaP}$ cells (Figure 2B, middle) $8 \beta$-VE2 causes AR downregulation, reduced cell survival and increased apoptosis. However, this occurred only at high $8 \beta$-VE2 concentrations, probably inconsistent with therapy options (Figure 3C-3D), and not upon ER $\beta$ upregulation. Therefore, the concept of AR-counteracting ER $\beta$ seems most convincing in therapy sequencing causing cross resistance upon appearance of AR splice variants (Figure 2, right).

We estimate that the antiandrogen function of ER $\beta$ activation has considerable advantages over established antiandrogens or future concepts of AR targeting that have been considered. An enduring therapeutic benefit from established AR LBD-binding antiandrogens may be restricted due to a potential antiandrogen-to-androgen conversion by LBD gain-of-function mutations, albeit only for a minority of therapy failures compared with the AR splice variant function [5]. In contrast to established antiandrogens, the drug $8 \beta$-VE2 a priori activates its target ER $\beta$; a comparable antagonist to agonist conversion due to selection of suitable AR mutant clones is therefore unlikely.

Furthermore, in the case of pre-existing gain-offunction AR mutations (e.g., T877A), the effectiveness of other, still feasible, antiandrogens (e.g., enzalutamide) for therapeutic sequencing is limited, as these AR blockers will no longer perform as true inhibitors of androgen signaling [27]. The ER $\beta$-mediated inhibition of AR signaling by downregulation will instead be in effect regardless of gain-of-function mutations, e.g., the T877A mutation [17]. Moreover, we presume that ER $\beta$ targeted AR inhibition is rather inoffensive, and toxic side effects may be limited compared with alternative antiandrogen considerations of AR degradation, antisense RNA-mediated AR downregulation or AR splice variant inhibition by targeting the rather unspecific target of the AR N-terminus [28-29]. Notwithstanding, an appropriate clinical application of ER $\beta$-selective drugs depents on an arguable useful dosage. In our in vitro experiments best performance was revealed at $5 \mu \mathrm{M}$ concentration which is in the same range we and others commonly use for the clinically approved drug abiraterone acetate as well as other antiandrogens [27]. In vivo studies with $8 \beta$-VE2 were conducted in micromolar range per $\mathrm{kg}$ body weigth [30-32]. A limitation to such drugs may be the ER $\beta$-selectivity restricted to a picomolar range [33]. This would imply that the major advantage of such drugs could be a lesser affinity to the AR (Supplementary Figure 1), especially promiscuous mutant AR, as compared to estradiol [17]. Therefore, major requirement for this ER $\beta$-mediated antiandrogen action in clinical applications will be the ER-subtype selectivity to avoid unwanted ER $\alpha$ activation. Interestingly, the more recently introduced ER $\beta$-selective agonist KB9520 also increases ER $\beta$ expression in malignancies other than prostate cancer [34-35]. We anticipate a most promising application of ER-subtype selective drugs as a tool to eliminate AR splice variants and cross resistance in therapy sequences. The function of ER $\beta$ as a tumor suppressor must not be true for all cancers and is also not true for all prostate cancers $[13,36]$. In AR-negative, e.g. neuroendrocrine prostate cancer a counteraction from $E R \beta$ on AR should be obsolete. Also AR-positive prostate cancers with combined mutational aberrations in the AR as in the cell modell CRW22Rv1 may be resistant to ER $\beta$-selective treatments with $8 \beta$-VE2. Our 8ß-VE2treatments of such prostate cancer cells confirmed the study from Colciago et al. [37]. 8ß-VE2-treatments successful for the VCaP AA cell model (Figure 2B) failed to diminish AR expression and to eradicate AR splice variants in the CRW22Rv1 model (data not shown). Fortunately, neuroendocrine prostate cancers and refractory therapy-resistant AR mutations are rare among prostate cancer patients [23, 27]. More conflicting results referring to the general tumor suppressor function of ER $\beta$ derived from a study by Wang et al. [38]. This study revealed higher ESR2 expression in a putative marker function in tumor tissue as compared normal prostate. Therefore, future studies are warranted to substantiate defined functions of the estrogen receptors.

To our knowledge, this is the first time ER $\beta$ has been considered a targetable antiandrogen structure in the connotation of therapy failure and therapy cross resistance in AR-targeted therapies. Future research and clinical applications are necessary to determine the potential of this approach in hitherto incurable mCRPC for optimal palliative effects, prolonged survival benefits or even curable measures. 


\section{MATERIALS AND METHODS}

\section{Cell lines}

The human prostate cancer cell line $\mathrm{VCaP}$ was obtained from LGC Standards (Teddington, England). $\mathrm{VCaP}$ revert ( $\mathrm{VCaP}$ rev) cells were generated by treating $\mathrm{VCaP}$ cells with rising concentrations of testosterone up to $1 \mathrm{nM}$ (Sigma-Aldrich, Taufkirchen, Germany) over a period of seven months, after which, the cells were further cultured in medium containing $1 \mathrm{nM}$ testosterone [21]. VCaP AA cells were treated with increasing concentrations (up to $5 \mu \mathrm{M}$ ) of abiraterone (Janssen-Cilag, Neuss, Germany) for seven weeks and then permanently cultured in medium containing the agent.

\section{Cell culture}

$\mathrm{VCaP}$ cells were cultured in phenol red-free DMEM (Life Technologies, Darmstadt, Germany) without L-glutamine or pyruvate and supplemented with $10 \%$ FBS, $1.25 \%$ penicillin/streptomycin, 5\% L-glutamine (PAN Technology, Carlstadt, USA), and 2\% sodium pyruvate (Life Technologies, Darmstadt, Germany). The medium for $\mathrm{VCaP}$ rev cells was supplemented with $1 \mathrm{nM}$ testosterone. The culture medium for $\mathrm{VCaP}$ AA cells was supplemented with $5 \mu \mathrm{M}$ abiraterone acetate hydrolyzed to abiraterone in ethanol/ $\mathrm{H}_{2} \mathrm{O}$ [22]. For subsequent experiments, the cells were cultured in medium containing dextran-coated charcoal (Sigma-Aldrich, Taufkirchen, Germany)-treated FBS.

\section{Measurements of cell survival and apoptosis induction}

For the measurement of proliferation and apoptosis, the ApoTox-Glo ${ }^{\mathrm{TM}}$ Triplex Assay (Promega, Fitchburg, USA) was used following the manufacturer's instructions. Signals were detected by the Synergy ${ }^{\mathrm{TM}} \mathrm{Mx}$ Plate reader (BioTek, Winooski, USA). All three VCaP cell variations ( $2 \times 10^{4}$ cells each) were cultured in 96-well plates. For pretrial experiments, concentrations between 5 and 50 $\mu \mathrm{M}$ of the ER $\beta$-specific agonist 8 $\beta$-VE2 (Bayer AG, Leverkusen, Germany) were added to the cell culture medium. DMSO (Carl Roth, Karlsruhe, Germany)-treated cells were used as a control. For further investigations, the three different $\mathrm{VCaP}$ cell variations were treated with either 5 or $25 \mu \mathrm{M} 8 \beta$-VE2. Analyses of cell proliferation and apoptosis were performed 24, 48, and $72 \mathrm{~h}$ after the beginning of treatment.

\section{Western blot analysis}

For protein isolation, $2 \times 10^{5}$ cells were plated in 6 -well plates. The three different $\mathrm{VCaP}$ cell variations were treated with either 5 or $25 \mu \mathrm{M} 8 \beta$-VE2 for $72 \mathrm{~h}$. Modified RIPA buffer (50 mM Tris pH 7.4, 1\% NP-40,
$0.25 \%$ Na-deoxycholate, $150 \mathrm{mM} \mathrm{NaCl}, 1 \mathrm{mM}$ EDTA) was used to isolate total cell lysates. Protein concentration was determined using the Bradford assay (Nanoquant, Carl Roth, Karlsruhe, Germany). For western blot analysis, 15 $\mu \mathrm{g}$ of total cell lysates were supplemented with 4x LDS sample buffer (Life Technologies, Darmstadt, Germany) containing 10\% DTT (Life Technologies, Darmstadt, Germany) and denatured at $70^{\circ} \mathrm{C}$ for $10 \mathrm{~min}$. The probes were loaded on NuPAGETM 4-12\% Bis-Tris gels (Life Technologies, Darmstadt, Germany) in MES buffer (Life Technologies, Darmstadt, Germany). The proteins were electrotransferred to a PVDF membrane (GE Healthcare, Munich, Germany) using a semidry blotting method. The membrane was blocked in 3\% BSA (Carl Roth $\mathrm{GmbH}$, Karlsruhe, Germany) or in 5\% dry milk (Carl Roth $\mathrm{GmbH}$, Karlsruhe, Germany) in Tris-buffered saline/Tween 20. The membrane was incubated with primary antibodies against AR (1:4000, NeoMarkers, Fremont, USA, \#1358), ER $\beta$ (1:10000, Cell Signaling, Danvers, USA, \#5513), PSA (1:4000, Cell Signaling, Danvers, USA, \#2475), or $\alpha$-tubulin (1:20000, Santa Cruz Biotechnology, Heidelberg, Germany) at $4^{\circ} \mathrm{C}$ overnight. Subsequently, the membrane was incubated with secondary goat antimouse IgG-HRP or goat anti-rabbit IgG-HRP (Dianova, Hamburg, Jackson Immuno-Research, Germany) in blocking buffer for $2 \mathrm{~h}$ at room temperature. The proteins were visualized by enhanced chemiluminescence according to the manufacturer's instructions (ECL Prime System, GE Healthcare, Freiburg, Germany). Signals were detected using a FluorChem Q (Biozym, Hessisch Oldendorf, Germany) and analyzed using FluorChem Q SA software (Biozym Scientific GmbH).

\section{Real-time reverse transcription (RT)-PCR}

For total RNA isolation, $2 \times 10^{5}$ cells were plated in 6-well plates. The three different $\mathrm{VCaP}$ cell variants were treated with either 5 or $25 \mu \mathrm{M} 8 \beta$-VE2 for $72 \mathrm{~h}$. Total RNA was isolated using the PeqGold Total RNA Kit (Peqlab, Erlangen, Germany). RNA concentrations were determined using a Nanodrop 2000C spectrophotometer (Thermo Scientific, Waltham, USA). Reverse transcription of the RNA was performed using SuperScript ${ }^{\circledR}$ II Reverse Transcriptase (Life Technologies, Darmstadt, Germany) cDNA polymerase; $1 \mu \mathrm{g}$ of RNA was used for the reaction. As a control for efficient cDNA synthesis, PCR with glyceraldehyde 3-phosphate dehydrogenase (GAPDH)-specific primers (fw-CCAGCAAGAGCACAAGAGGAAGAG; revAGCACAGGGATACTTTATTAGATG) was performed. For the real-time RT-PCR analysis, $40 \mathrm{ng}$ of cDNA was used as template. Platinum ${ }^{\circledR}$ SYBR ${ }^{\circledR}$ Green qPCR SuperMix-UDG with ROX (Life Technologies, Darmstadt, Germany) was used for signal detection. The threshold cycle (CT) values for AR expression (fw-AGGAACTCGATCGTATCATTGC, rev- 
CTCTGCCATCATTTCCGGAA) were normalized to expression levels of the housekeeping genes hypoxanthine phosphoribosyltransferase (HPRT) (fw-ACCCTTTCCAAATCCTCAGC, revGTTATGGCGACCCGCAG) and lactate dehydrogenase A (LDHA) (fw-GGAGATCCATCATCTCTCCC, revGGCCTGTGCCATCAGTATCT). Signal detection was performed using a 7900HT sequence detection system (Applied Biosystems, Darmstadt, Germany), and data were analyzed using SDS 2.3 software.

\section{ACKNOWLEDGMENTS}

We thank Rovena Halpape, Lisa Hartmund, Valerie Unterkircher and Marion Striepe for technical assistance. This work was supported by the Deutsche Forschungsgemeinschaft (to P. Thelen: TH 389/3-1; to P. Burfeind: BU 992/6-1; to H. Jarry: JA 398/11-1 and to F. Bremmer: BR 4700/1-1). We acknowledge support by the Open Access Publication Funds of Goettingen University.

\section{CONFLICTS OF INTEREST} interests.

The authors declare that they have no competing

\section{REFERENCES}

1. Rathkopf DE, Smith MR, de Bono JS, Logothetis CJ, Shore ND, de Souza P, Fizazi K, Mulders PFA, Mainwaring P, Hainsworth JD, Beer TM, North S, Fradet Y, et al. Updated interim efficacy analysis and long-term safety of abiraterone acetate in metastatic castration-resistant prostate cancer patients without prior chemotherapy (COU-AA-302). Eur Urol. 2014; 66: 815-825.

2. Knudsen KE, Penning TM. Partners in crime: deregulation of AR activity and androgen synthesis in prostate cancer. Trends Endocrinol Metab. 2010; 21: 315-324.

3. Caffo O, Lunardi A, Trentin C, Veccia A, Galligioni E. Optimal sequencing of new drugs in metastatic castrationresistant prostate cancer: dream or reality? Curr Drug Targets. 2016; 17:1301-1308.

4. Romanel A, Gasi Tandefelt D, Conteduca V, Jayaram A, Casiraghi N, Wetterskog D, Salvi S, Amadori D, Zafeiriou Z, Rescigno P, Bianchini D, Gurioli G, Casadio V, et al. Plasma AR and abiraterone-resistant prostate cancer. Sci Transl Med. 2015; 7:312re10.

5. Balbas MD, Evans MJ, Hosfield DJ, Wongvipat J, Arora VK, Watson PA, Chen Y, Greene LG, Shen Y, Sawyers CL. Overcoming mutation-based resistance to antiandrogens with rational drug design. ELife. 2013; 2: e00499. doi: 10.7554/eLife.00499.

6. Seton-Rogers S. Therapeutic resistance: two steps ahead. Nat Rev Cancer. 2013;13: 382-383.
7. Josan JS, Katzenellenbogen JA. Designer antiandrogens join the race against drug resistance. ELife. 2013; 2: e00692.

8. Antonarakis ES, Lu C, Wang H, Luber B, Nakazawa M, Roeser JC, Chen Y, Mohammad TA, Chen Y, Fedor LH, Lotan TL, Zheng Q, de Marzo AM, et al. AR-V7 and resistance to enzalutamide and abiraterone in prostate cancer. New Engl J Med. 2014; 371: 1028-1038.

9. Karantanos T, Evans CP, Tombal B, Thompson TC, Montironi R, Isaacs WB. Understanding the mechanisms of androgen deprivation resistance in prostate cancer at the molecular level. Eur Urol. 2015; 67: 470-479.

10. Slusarz A, Jackson GA, Day JK, Shenouda NS, Bogener JL, Browning JD, Fritsche KL, MacDonald RS, BeschWilliford CL, Lubahn DB. Aggressive prostate cancer is prevented in ER $\alpha \mathrm{KO}$ mice and stimulated in ER $\beta \mathrm{KO}$ TRAMP mice. Endocrinology. 2012; 153: 4160-4170.

11. Bardin A, Boulle N, Lazennec G, Vignon F, Pujol P. Loss of ERbeta expression as a common step in estrogen-dependent tumor progression. Endocr Relat Cancer. 2004; 11: 537-551.

12. Gabal SM, Habib FM, Helmy DO, Ibrahim MF. Expression of estrogen receptor-B (ER-B) in benign and malignant prostatic epithelial cells and its correlation with the clinicopathological features. J Egypt Natl Canc Inst. 2007; 19: 239-248.

13. Bonkhoff $H$, Berges $H$. The evolving role of oestrogens and their receptors in the development and progression of prostate cancer. Eur Urol. 2009; 55: 533-542.

14. Cheng J, Lee EJ, Madison LD, Lazennec G. Expression of estrogen receptor beta in prostate carcinoma cells inhibits invasion and proliferation and triggers apoptosis. FEBS Lett. 2004; 566: 169-172.

15. Hurtado A, Pinós T, Barbosa-Desongles A, López-Avilés S, Barquinero J, Petriz J, Santamaria-Martínez A, Morote J, de Torres I, Bellmunt J, Reventós J, Munell F. Estrogen receptor beta displays cell cycle-dependent expression and regulates the G1 phase through a non-genomic mechanism in prostate carcinoma cells. Cell Oncol. 2008; 30: 349-365.

16. Walton TJ, Li G, Seth R, McArdle RE, Bishop MC, Rees RC. DNA demethylation and histone deacetylation inhibition co-operate to re-express estrogen receptor beta and induce apoptosis in prostate cancer cell-lines. Prostate. 2008; 68: 210-222.

17. Stettner M, Kaulfuss S, Burfeind P, Schweyer S, Strauss A, Ringert RH, Thelen P. The relevance of estrogen receptorbeta expression to the antiproliferative effects observed with histone deacetylase inhibitors and phytoestrogens in prostate cancer treatment. Mol Cancer Ther. 2007; 6: 2626-2633.

18. Thelen P, Scharf JG, Burfeind P, Hemmerlein B, Wuttke W, Spengler B, Christoffel V, Ringert RH, Seidlová-Wuttke D. Tectorigenin and other phytochemicals extracted from leopard lily Belamcanda chinensis affect new and established targets for therapies in prostate cancer. Carcinogenesis. 2005; 26: 1360-1367. 
19. Thelen P, Wuttke D, Seidlová-Wuttke D. Phytoestrogens selective for the estrogen receptor beta exert antiandrogenic effects in castration resistant prostate cancer. J Steroid Biochem Mol Biol. 2014; 139: 290-293.

20. Nilsson S, Koehler KF, Gustafsson JA. Development of subtype-selective oestrogen receptor-based therapeutics. Nat Rev Drug Discov. 2011; 10: 778-792.

21. Thelen P, Heinrich E, Bremmer F, Trojan L, Strauss A. Testosterone boosts for treatment of castration resistant prostate cancer: an experimental implementation of intermittent androgen deprivation. Prostate. 2013; 73: 1699-1709.

22. Bremmer F, Jarry H, Strauß A, Behnes CL, Trojan L, Thelen P. Increased expression of CYP17A1 indicates an effective targeting of the androgen receptor axis in castration resistant prostate cancer (CRPC). Springerplus. 2014; 3: 574.

23. Steinestel J, Luedeke M, Arndt A, Schnoeller TJ, Lennerz JK, Wurm C, Maier C, Cronauer MV, Steinestel K, Schrader AJ. Detecting predictive androgen receptor modifications in circulating prostate cancer cells. Oncotarget. 2015 April 23. doi: 10.18632/oncotarget.3925. [Epub ahead of print].

24. Buttigliero C, Tucci M, Bertaglia V, Vignani F, Bironzo P, Di Maio M, Scagliotti GV. Understanding and overcoming the mechanisms of primary and acquired resistance to abiraterone and enzalutamide in castration resistant prostate cancer. Cancer Treat Rev. 2015; 41: 884-892.

25. Al Nakouzi N, Le Moulec S, Albigès L, Wang C, Beuzeboc P, Gross-Goupil M, de La Motte Rouge T, Guillot A, Gajda D, Massard C, Gleave M, Fizazi K, Loriot Y. Cabazitaxel remains active in patients progressing after docetaxel followed by novel androgen receptor pathway targeted therapies. Eur Urol. 2015; 68: 228-235.

26. Nilsson S, Gustafsson JA. Estrogen receptors: therapies targeted to receptor subtypes. Clin Pharmacol Ther. 2011; 89: 44-55.

27. Lallous N, Volik SV, Awrey S, Leblanc E, Tse R, Murillo J, Singh K, Azad AA, Wyatt AW, LeBihan S, Chi KN, Gleave ME, Rennie PS, et al. Functional analysis of androgen receptor mutations that confer anti-androgen resistance identified in circulating cell-free DNA from prostate cancer patients. Genome Biol. 2016; 17: 10. doi: 10.1186/ s13059-015-0864-1.

28. Dellis A, Papatsoris AG. Phase I and II therapies targeting the androgen receptor for the treatment of castration resistant prostate cancer. Expert Opin Investig Drugs. 2016; 25: 697-707.

29. Agarwal N, Di Lorenzo G, Sonpavde G, Bellmunt J. New agents for prostate cancer. Ann Oncol. 2014; 25: 1700-1709.

30. Hertrampf T, Seibel J, Laudenbach U, Fritzemeier KH, Diel P. Analysis of the effects of oestrogen receptor alpha (ERalpha)- and ERbeta-selective ligands given in combination to ovariectomized rats. Br J Pharmacol. 2008; 153:1432-1437.

31. Yang YH, Ngo D, Jones M, Simpson E, Fritzemeier $\mathrm{KH}$, Morand EF. Endogenous estrogen regulation of inflammatory arthritis and cytokine expression in male mice, predominantly via estrogen receptor alpha. Arthritis Rheum. 2010; 62:1017-1025.

32. Hegele-Hartung C, Siebel P, Peters O, Kosemund D, Müller G, Hillisch A, Walter A, Kraetzschmar J, Fritzemeier KH. Impact of isotype-selective estrogen receptor agonists on ovarian function. Proc Natl Acad Sci USA. 2004; 101:5129-5134.

33. Hillisch A, Peters O, Kosemund D, Müller G, Walter A, Schneider B, Reddersen G, Elger W, Fritzemeier KH. Dissecting physiological roles of estrogen receptor alpha and beta with potent selective ligands from structure-based design. Mol Endocrinol. 2004; 18:1599-1609.

34. Pinton G, Zonca S, Manente AG, Cavaletto M, Borroni E, Daga A, Jithesh PV, Fennell D, Nilsson S, Moro L. SIRT1 at the crossroads of AKT1 and ER $\beta$ in malignant pleural mesothelioma cells. Oncotarget. 2016; 7: 14366-14379. doi: 10.18632/oncotarget.7321.

35. Manente AG, Pinton G, Zonca S, Cilli M, Rinaldi M, Daga A, Nilsson S, Moro L. Intracellular lactate-mediated induction of estrogen receptor beta $(\mathrm{ER} \beta)$ in biphasic malignant pleural mesothelioma cells. Oncotarget. 2015; 6: 25121-25134. doi: 10.18632/oncotarget.4486.

36. Nelson AW, Tilley WD, Neal DE, Carroll JS. Estrogen receptor beta in prostate cancer: friend or foe? Endocr Relat Cancer. 2014; 21: T219-34.

37. Colciago A, Ruscica M, Mornati O, Piccolella M, Montagnani-Marelli M, Eberini I, Festuccia C, Magni P, Motta M, Negri-Cesi P. In vitro chronic administration of ERbeta selective ligands and prostate cancer cell growth: hypotheses on the selective role of 3betaadiol in AR-positive RV1 cells. Biomed Res Intl. 2014; 2014:801473.

38. Wang M, Takahashi A, Liu F, Ye D, Ding Q, Qin C, Yin C, Zhang Z, Matsuda K, Kubo M, Na R, Lin X, Jiang H, et al. Large-scale association analysis in Asians identifies new susceptibility loci for prostate cancer. Nat Commun. 2015; 6:8469.

39. Cully M, Shiu J, Piekorz RP, Muller WJ, Done SJ, Mak TW. Transforming acidic coiled coil 1 promotes transformation and mammary tumorigenesis. Cancer Res. 2005; 65:10363-10370.

40. Kaulfuss S, Grzmil M, Hemmerlein B, Thelen P, Schweyer S, Neesen J, Bubendorf L, Glass AG, Jarry H, Auber B, Burfeind P. Leupaxin, a novel coactivator of the androgen receptor, is expressed in prostate cancer and plays a role in adhesion and invasion of prostate carcinoma cells. Mol Endocrinol. 2008; 22:1606-1621. 